\title{
BUCKLING BEHAVIOR OF EQUAL ANGLE RESTRAINED BY WELD SEAM AT BOTH ENDS: NUMERICAL ANALYSIS
}

\author{
Zhong-Wei Zhao ${ }^{1,2, *}$, Xiong-Tao Fan ${ }^{1}$, Xiang-Yang Jian ${ }^{1}$, Bing Liang ${ }^{3}$ and Hai-Qing Liu ${ }^{1}$ \\ 1 School of Civil Engineering, Liaoning Technical University, Fuxin 123000, China; \\ 2 School of Civil Engineering, Southeast University, Nanjing, Jiangsu, 211189, China \\ 3 School of Mechanics and Engineering, Liaoning Technical University, Fuxin 123000, China \\ *(Corresponding author: E-mail: zhaozhongwei@lntu.edu.cn)
}

\section{A B S T RA C T}

Welding the reinforced component on the surface of a steel structure is a common method for reinforcing steel structures in practical engineering. Intermittent weld has been recognized as an efficient method for reducing the amount of field welding work and the cost of reinforcing work. The angles welded by intermittent weld have been widely utilized in practical engineering, such as the strengthening of steel column presented in this work. However, the mechanical behavior of angles welded by intermittent weld has not been clearly clarified. The buckling behavior of angles with weld limbs (AWL) is systematically investigated in this work to determine their loading capacity. The buckling factor and slenderness of AWLs are derived through a numerical analysis. The influences of weld length (Lw), yield strength (fy), residual stress, and initial geometrical imperfection on the buckling factor $(\varphi \mathrm{cr})$ are also investigated. The results indicate that material strength can be fully played out when applying intermittent weld. The results derived in this paper can provide reference for the design of angles welded by intermittent weld.
A R T I C LE H IS TO RY

\begin{tabular}{ll}
\hline & \\
Received: & 8 March 2020 \\
Revised: & 12 September 2020 \\
Accepted: & 18 September 2020
\end{tabular}

\section{K E Y W O R D S}

Angles with weld limbs;

Buckling factor;

Compression-flexure member;

Bearing capacity;

Finite element analysis

\section{Introduction}

Reinforcing steel columns has become an increasingly common practice in practical engineering due to the changes in their structural use, corrosion, and structural damage caused by incidental load, such as fire or seismic action [1-2]. Rectangular steel columns have been widely used in actual projects due to their ease of connection to the beam. Therefore, an efficient method for strengthening rectangular steel columns must be developed.

Steel columns are mainly strengthened by increasing their number of member sections, which in turn can be achieved by welding additional members to the original members and by welding steel angles to the steel columns. Steel angles are traditionally welded through a continuous weld, but this method is time consuming, expensive, and requires large-scale fieldwork. In addition, field welding is a labor-intensive task that does not guarantee a high weld quality. All these factors significantly increase the cost of reinforcement projects. The extent of field welding work also affects the reinforcement progress. Therefore, the continuous weld method must be replaced with intermittent weld or other efficient welding methods.

Intermittent weld can be used to replace continuous weld and to reduce the amount of weld workload in construction sites without changing the reinforcement effect as shown in [3-4]. However, the buckling behavior of angles that are welded via intermittent weld has not been thoroughly investigated in the literature. The force transferring mechanism between the angle and steel column also greatly differs from that of RC column reinforcement [5-8]. The buckling of steel members has always been a hot topic among researchers and engineers, and many mature research findings have been obtained in recent years [9-13]. For instance, Hussain [14-15] proposed an effective stress-strain relationship representing the typical failure modes and initial imperfections and this effective stress-strain relationship can be used for the direct analysis of steel structures made of angle sections without use of the effective length method. Ban et al. [16] investigated the overall buckling behavior of high-strength steel welded section columns. Li et al. [17-18] employed numerical and experimental methods to investigate 12 Q690 HS steel welded box and I-section columns. Nie et al. [19] performed an experiment on eight box columns with varying cross sections, slenderness, and eccentricities. Previous studies on buckling have mainly focused on members that are subjected to axial load, while only few studies have examined the buckling of compression-flexure members. Although the mechanical behavior of angles has been widely investigated in the literature [14-17], such behavior greatly varies when applied for strengthening steel columns. The failure mode of angle welded by intermittent weld seam (tested by the authors) is shown in Fig. 1. It can be seen that the failure mode of angle welded by intermittent weld is different with that welded by continuous weld. The load capacity of angles welded by intermittent weld has not been revealed. This work investigates the axial loading capacity of angles that are welded by an intermittent weld seam, which forms the premise for investigating the force transferring mechanism between angles and steel columns

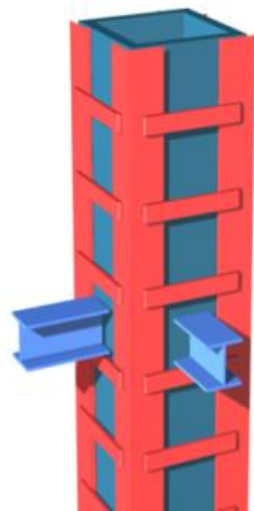

(a) Schematic

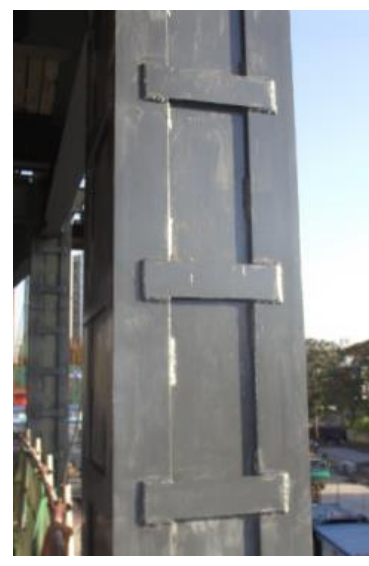

(b) Practical project

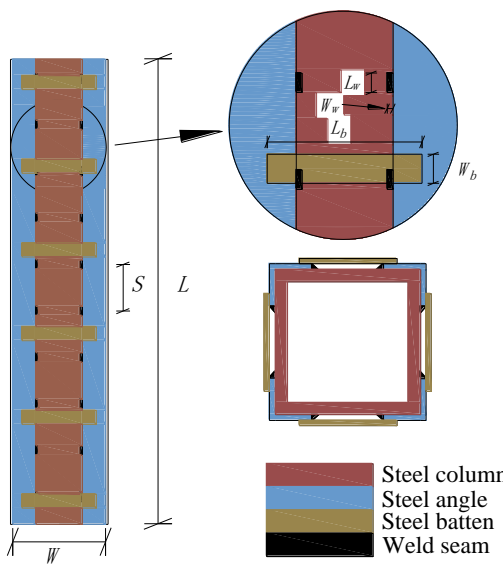

(c) Parameters of the reinforced scheme

Fig. 1 Steel column reinforcement method 


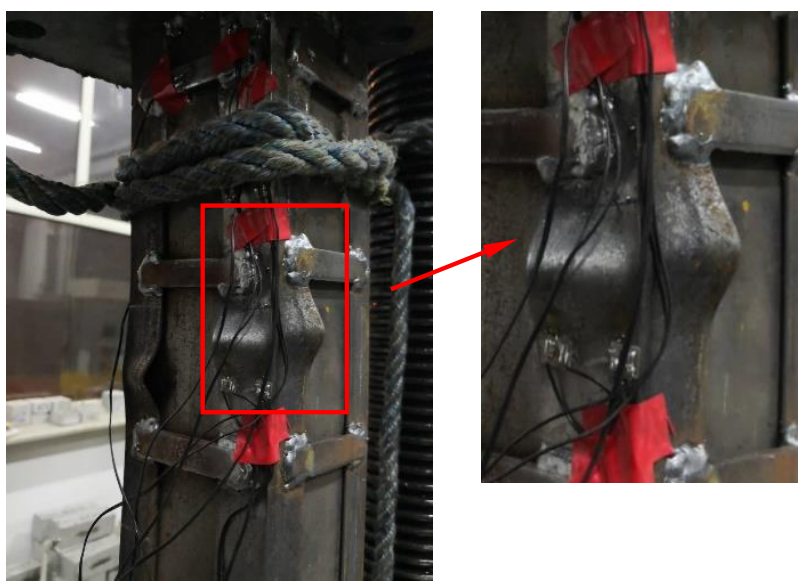

Fig. 2 Failure mode of angle welded by intermittent weld seam

\section{Detailed description of angles with weld limbs (AWL)}

When steel angles are used to strengthen box steel columns, both limbs are welded to the columns. The steel angles are subjected to eccentric loading when the column is subjected to axial load. The characteristics of an AWL that is subjected to both axial force and moment (Fig. 3) may greatly differ from those of angles that are only subjected to axial force. The appearance of moment will reduce the loading capacity for load in the axial direction. The influence of moment is considered in designing a compression-flexure member in GB50017[24] by using Eq. 1, which can also be used to assess the reliability of a member. However, the buckling capacity of a specified compression-flexure member, such as AWL, cannot be easily calculated.

$\frac{N}{\varphi_{x} A f}+\frac{\beta_{m x} M_{x}}{\gamma_{x} W_{1 x}\left(1-0.8 N / N^{\prime}{ }_{E x}\right)} \leq 1$,

where $\mathrm{N}$ is the design value of axial force, $\varphi_{x}$ is the buckling factor in the plane of the bending moment, $M_{x}$ is the maximum moment along the member, $\beta_{m x}$ is the equivalent moment factor, $\mathrm{W}_{1 \mathrm{x}}$ is the gross section modulus, and $N_{E x}^{\prime}=\pi^{2} E A /\left(1.1 \lambda^{2}\right)$.
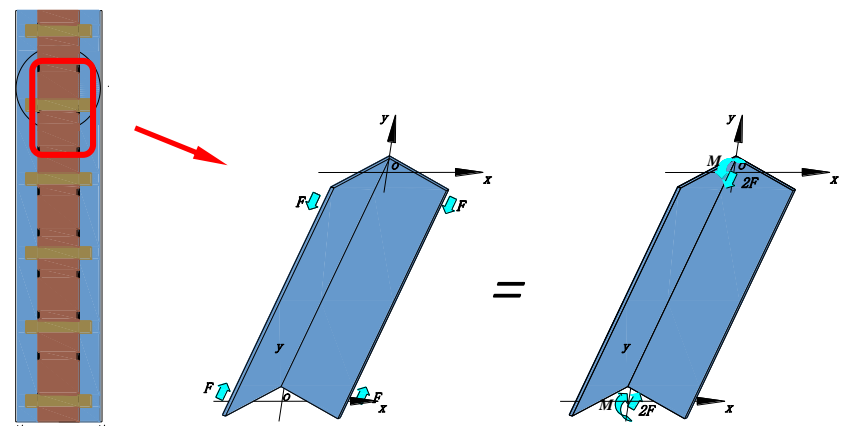

Fig. 3 Schematic of AWL

The detailed dimensional size of AWL is shown in Fig. 4, where $L$ denotes the overall length of AWL, $L_{\mathrm{w}}$ denotes the length of the weld seam at both ends of the AWL, and $t$ and $w$ denote the thickness and width of the AWL, respectively.

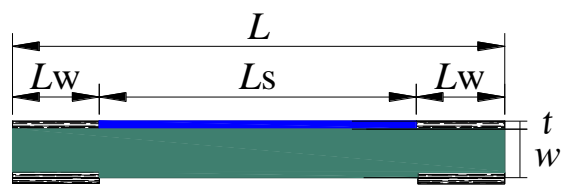

Fig. 4 Dimensional size of AWL

This work aimed to propose a simplified method for computing the axial bearing capacity of AWLs. The buckling factor $\varphi_{c f}$ of AWL in this work indicated the ratio of axial bearing capacity $\left(f_{\mathrm{u}}\right)$ and $\mathrm{A} f_{\mathrm{y}}$. Given that the value of $\varphi_{c f}$ automatically considers the influence of bending moment, the loading capacity of AWLs with a specified section can be easily derived when the buckling factor is known. The relationship between $\varphi_{c f}$ and $\lambda_{\mathrm{n}}$ was also systematically investigated in this work. $\lambda_{\mathrm{n}}$ denotes the slenderness ratio $\lambda$ normalized by the yield strength $f_{\mathrm{y}}$ of steel as shown in Eq. (2).

$\lambda=\underline{\lambda} \frac{f_{y}}{1}$,(2) Given that the rotation of both ends of the AWL was restrained by the $\pi$ we Therefore, the computational length factor was set to 0.5 . The slenderness of AWL can be derived as $i_{x}$ where denotes the gyration radius about the $x$-axis.

$\lambda=\frac{L-2 L_{w}}{2 i_{x}}=\frac{L_{s}}{2 i_{x}}$

\section{Finite element model}

Finite element analysis was conducted with the finite element code ANSYS to investigate the relationship between $\varphi_{c f}$ and $\lambda_{n}$. All components were modeled with the SOLID45 element. The mesh at the weld seam was refined to obtain accurate results. The ideal elastic-plastic model was adopted in the numerical analysis. The constitutive relationship of steel is presented in Fig. 5 . The weld seam was not considered in the FE model for simplification and under the premise that the weld cannot encounter failure before the buckling of AWL. Vertical displacement was applied at the weld zone (Fig. 6.), and the translational degrees of the weld zone were fixed.

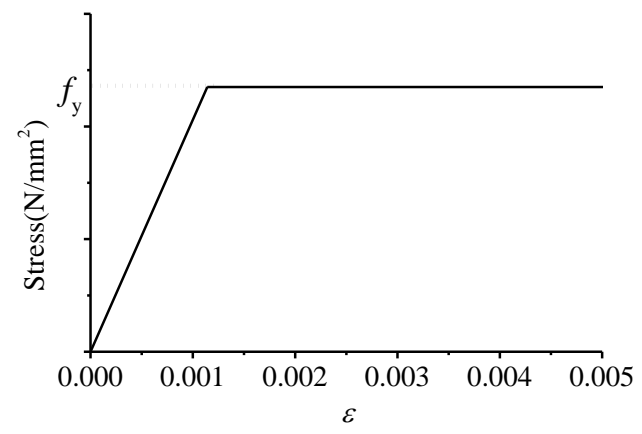

Fig. 5 Constitutive relationship of steel

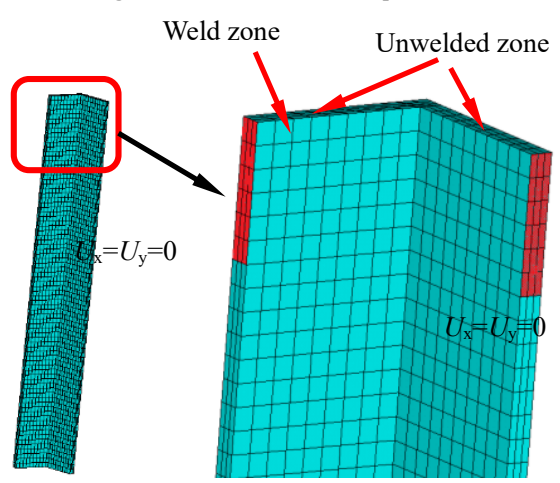

Fig. 6 Restraint condition at the end of AWL 


\section{Validation of numerical model}

The experiment was conducted to validate the reliability of FE model. The section of AWL was $L 30 \times 3$ and the length were set to 200,400 and $500 \mathrm{~mm}$. The detailed information about test specimen was shown in Tab. 1. A total of 9 specimens were tested and the load was applied in displacement controlling method with a rate equaling to $0.1 \mathrm{~mm} / \mathrm{s}$. The meaning of each symbol was shown in Fig. 4. The composition of test specimens was shown in Fig. 7. The experiment was conducted by utilizing universal testing machine with measuring range of $300 \mathrm{kN}$, as shown in Fig. 8. The compression force was applied and the deformation of one specimen was shown in Fig. 9. The loaddisplacement curves of each specimen were shown in Fig. 10. The ultimate load of each specimen derived in the experiment was shown in Tab. 2. It can be seen form the results that the ultimate load is obviously affected by the $L_{\mathrm{w}}$ and $L$.

The expected failure mode was the symmetric bending failure which was shown in Fig. 9. The failure mode of each specimen derived in experiment was shown in Fig. 11. It can be seen that the failure mode of SJ-200-60 was local buckling of AWL. The SJ-400-60 and SJ-500-60 failed by the fracture of weld and local buckling of AWL. The failure modes of SJ-400-60 and SJ-500-60 was not consistent with the actual condition. This failure mode can be avoided due to the existence of steel column.

The standard tension test was conducted to determine the ultimate load which was the most important parameter in present work. The test coupon was taken from the AWL and the standard tension test was performed three times and the mean value was extracted, as shown in Fig. 12 and Fig. 13. The standard tension test indicated that the ultimate load of test specimen was $108 \mathrm{kN}$. Then the buckling factor of each specimen was computed and compared with that derived in FEA. The comparison was shown in Fig. 14. It can be seen that the buckling factor derived in numerical analysis agreed well with the experiment and the reliability of FE model can be validated

Table 1

Detailed information about test specimens

\begin{tabular}{|c|c|c|c|c|c|c|}
\hline Specimen number & Section $(\mathrm{mm})$ & $L(\mathrm{~mm})$ & $L_{\mathrm{w}}(\mathrm{mm})$ & $L_{\mathrm{s}}(\mathrm{mm})$ & Normalized slenderness $\lambda_{\mathrm{n}}$ & Computational buckling factor $\varphi$ \\
\hline SJ-200-40 & $L 30 \times 3$ & 200 & 40 & 120 & 0.1105 & 0.7904 \\
\hline SJ-400-40 & $L 30 \times 3$ & 400 & 40 & 320 & 0.2946 & 0.7801 \\
\hline SJ-500-60 & $L 30 \times 3$ & 500 & 40 & 420 & 0.3866 & 0.7728 \\
\hline SJ-200-20 & $\mathrm{L} 30 \times 3$ & 200 & 20 & 160 & 0.1473 & 0.4758 \\
\hline SJ-400-20 & $\mathrm{L} 30 \times 3$ & 400 & 20 & 360 & 0.3314 & 0.4393 \\
\hline SJ-500-20 & $\mathrm{L} 30 \times 3$ & 500 & 20 & 460 & 0.4235 & 0.4191 \\
\hline SJ-200-60 & $\mathrm{L} 30 \times 3$ & 200 & 60 & 120 & 0.0736 & 0.9808 \\
\hline SJ-400-60 & $\mathrm{L} 30 \times 3$ & 400 & 60 & 320 & 0.2577 & 0.9776 \\
\hline SJ-500-60 & $\mathrm{L} 30 \times 3$ & 500 & 60 & 420 & 0.3498 & 0.9742 \\
\hline
\end{tabular}

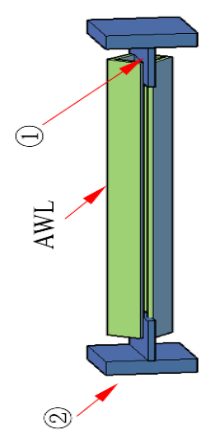

Fig. 7 Composition of test specimen

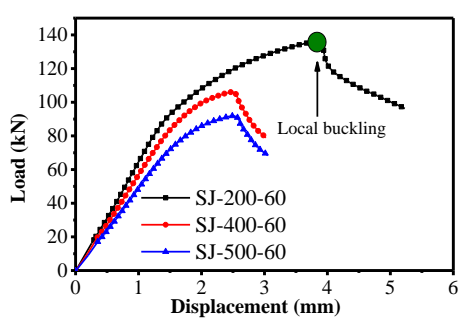

a) $L_{\mathrm{w}}=60 \mathrm{~mm}$

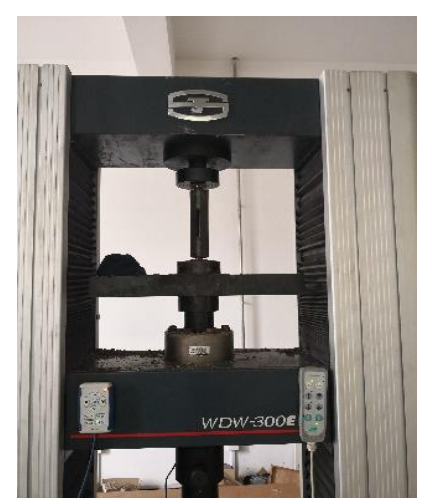

Fig. 8 Loading device

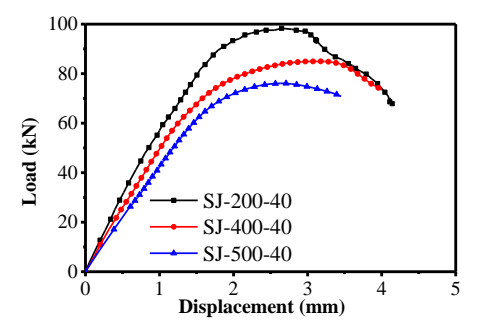

b) $L_{\mathrm{w}}=40 \mathrm{~mm}$

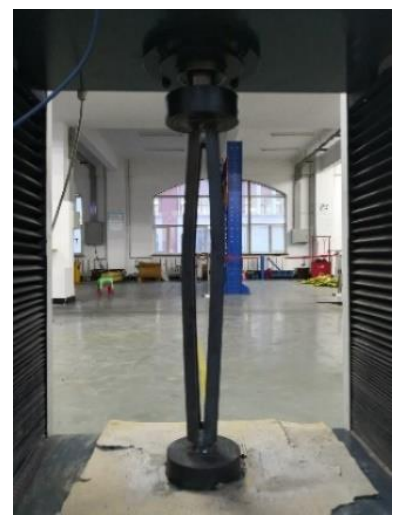

Fig. 9 Deformation of SJ-500-20

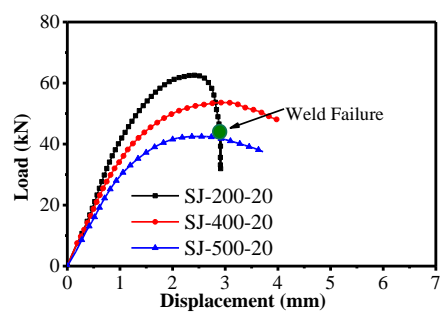

c) $L_{\mathrm{w}}=20 \mathrm{~mm}$

Table 2

Fig. 10 Load-displacement curves of test specimens

Ultimate load of each specimen

\begin{tabular}{ccc}
\hline Specimen number & Ultimate load $(\mathrm{kN})$ & Specimen number \\
\hline SJ-200-60 & 135.056 & SJ-400-20 \\
SJ-200-40 & 90.991 & SJ-500-60 \\
SJ-200-20 & 62.532 & SJ-500-40 \\
SJ-400-60 & 103.950 & SJ-500-20 \\
SJ-400-40 & 97.875 & 76.005 \\
\hline
\end{tabular}



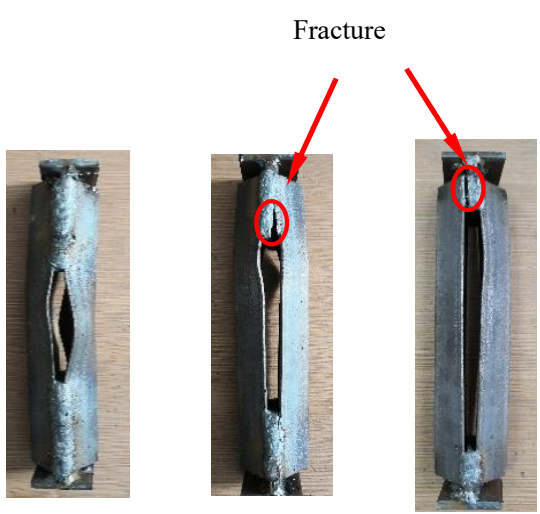

a) SJ-200-60

b) $\mathrm{SJ}-200-40$

c) SJ-200-20
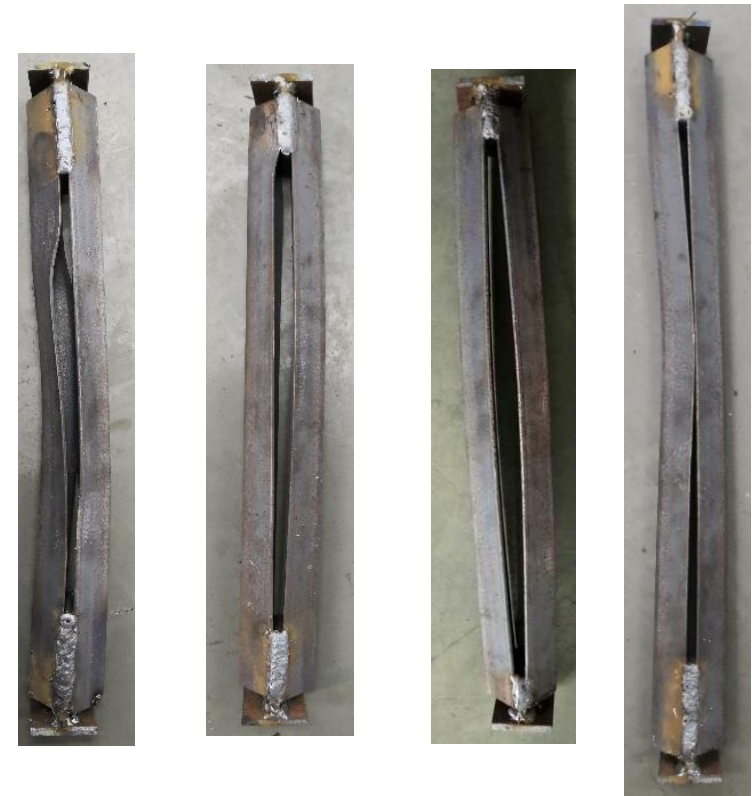

d) SJ-400-60

e) $\mathrm{SJ}-400-40$

f) $\mathrm{SJ}-400-20$

g) SJ-500-60

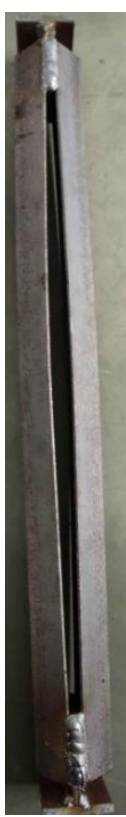

h) SJ-500-40

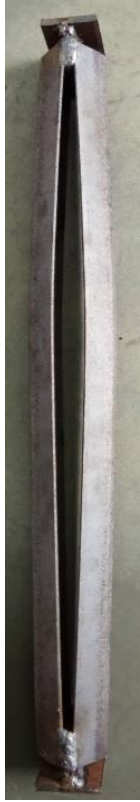

i) $\mathrm{SJ}-500-20$

Fig. 11 Failure mode of each specimen

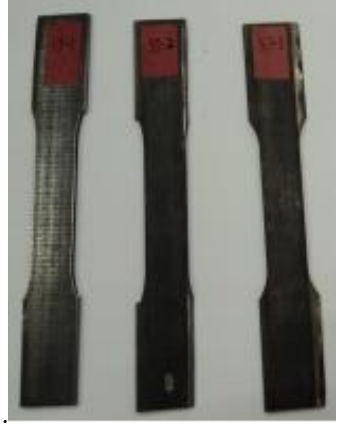

Fig. 12 Specimen in standard tension test

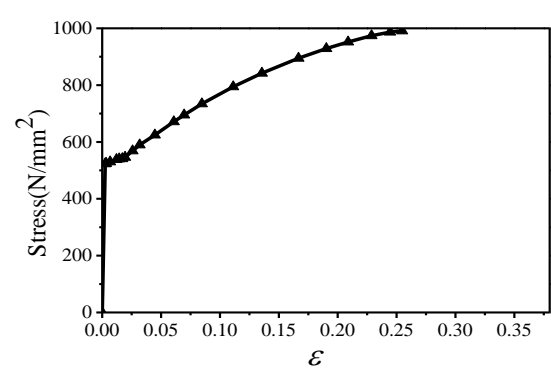

Fig. 13 The stress-strain curve

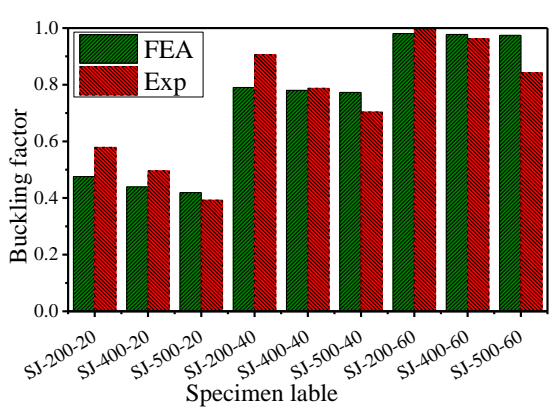

Fig. 14 Comparison of buckling factor

\section{Effects of initial geometric imperfections}

The AWL with a typical sectional scale that is often used in actual projects was analyzed in this paper. Tab. 3 presents detailed information on the specimens used in the numerical analysis. The yield strength of steel was varied to investigate its influence on $\varphi_{c f}$.

The effect of initial geometrical imperfection was investigated in this section. Linear buckling analysis was conducted and an initial imperfection was applied according to the buckling model. The buckling mode of $L 45 \times 5$ angle corresponding to $L_{w}=90 \mathrm{~mm}$ is shown in Fig. 16. It can be observed that the first buckling mode is not suitable as it is not consistent with the failure mode shown in Fig. 2. The failure mode indicated by the first buckling mode cannot happened due to the existence of steel column. So, the geometrical imperfection is applied according to the fourth buckling mode. The amplitude of the initial imperfection was set to $1 \%$ of the column height. Static analysis was conducted afterward. The large deformation effect was considered by 'nlgeom,1' command. The Newton-Raphson option was specified to solve the nonlinear problems. The initial substep number was set to 1000 and the max substep number was set to 2000. The influence of geometrical imperfections is shown in Fig. 15. The buckling factor $\varphi_{c f}$ was almost not influenced by geometrical imperfection when the amplitude was set to $1 \%$ of the column height. This factor greatly differed from the axially compressed bar. Given that the influence of initial imperfection can be neglected, the influence of initial geometrical imperfection was not considered in the analysis.

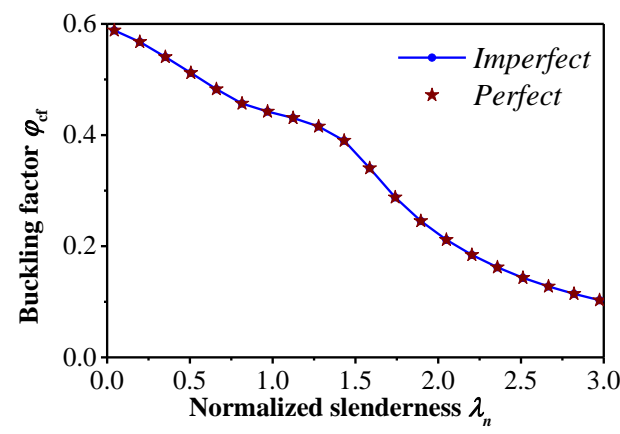

a) $f_{\mathrm{y}}=235 \mathrm{MPa}, L_{w}=40 \mathrm{~mm}, L 45 \times 5$

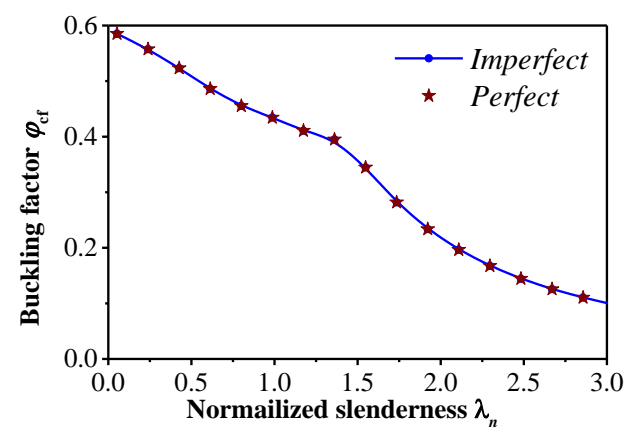

b) $f_{\mathrm{y}}=345 \mathrm{MPa}, L_{w}=40 \mathrm{~mm}, L 45 \times 5$

Fig. 15 Influence of geometric imperfection on buckling factor 
Table 3

Detailed information on the specimens

\begin{tabular}{|c|c|c|c|c|c|}
\hline Number & Section & $f_{\mathrm{y}}(\mathrm{MPa})$ & $A\left(\mathrm{~cm}^{2}\right)$ & $i_{\mathrm{y}}(\mathrm{cm})$ & $F_{y}(\mathrm{kN})$ \\
\hline 1 & $L 50 \times 5$ & 235 & 4.80 & 0.98 & 112.8 \\
\hline 2 & $L 56 \times 5$ & 235 & 5.41 & 1.1 & 127.1 \\
\hline 3 & $L 63 \times 5$ & 235 & 6.14 & 1.25 & 144.3 \\
\hline 4 & $L 45 \times 5$ & 235 & 4.29 & 0.88 & 100.8 \\
\hline 5 & $L 45 \times 5$ & 345 & 4.29 & 0.88 & 148.0 \\
\hline 6 & $L 45 \times 5$ & 610 & 4.29 & 0.88 & 261.7 \\
\hline 7 & $L 70 \times 5$ & 235 & 6.87 & 1.39 & 161.4 \\
\hline 8 & $L 70 \times 5$ & 345 & 6.87 & 1.39 & 237.0 \\
\hline 9 & $L 70 \times 5$ & 420 & 6.87 & 1.39 & 288.5 \\
\hline 10 & $L 70 \times 5$ & 610 & 6.87 & 1.39 & 419.1 \\
\hline 11 & $L 40 \times 5$ & 235 & 3.79 & 0.78 & 89.1 \\
\hline 12 & $L 36 \times 5$ & 235 & 3.38 & 0.7 & 79.4 \\
\hline 13 & $L 56 \times 8$ & 235 & 8.37 & 1.09 & 196.7 \\
\hline 14 & $L 63 \times 8$ & 235 & 9.51 & 1.23 & 223.5 \\
\hline 15 & $L 70 \times 8$ & 235 & 10.7 & 1.37 & 251.5 \\
\hline 16 & $L 75 \times 8$ & 235 & 11.5 & 1.47 & 270.3 \\
\hline 17 & $L 75 \times 8$ & 345 & 11.5 & 1.47 & 396.7 \\
\hline 18 & $L 75 \times 8$ & 420 & 11.5 & 1.47 & 483.0 \\
\hline 19 & $L 75 \times 8$ & 610 & 11.5 & 1.47 & 701.5 \\
\hline 20 & $L 200 \times 20$ & 235 & 76.5 & 3.93 & 1797.8 \\
\hline
\end{tabular}

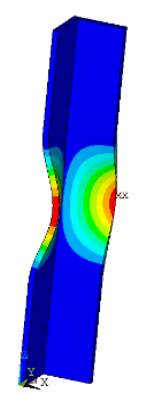

a) The first buckling mode

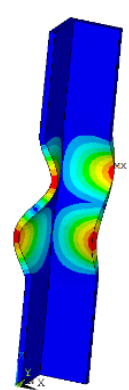

b) The second buckling mode

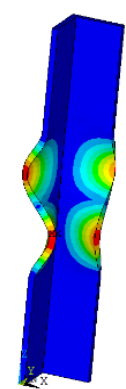

c) The third buckling mode

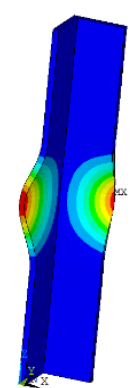

d) The fourth buckling mode

Fig. 16 The first four buckling modes

\section{Influence of residual stress}

The influence of residual stress on the buckling capacity of the angle was systematically investigated in this section. The distribution mode of residual stress in the length direction is illustrated in Fig. 17, where "+" denotes the tensioning stress, while "-" denotes the compression stress. The residual stress was applied through initial stress in general finite element code ANSYS. The values of $\beta$ were set to $0,0.3,0.5$, and 0.7 . The contour of residual stress is illustrated in Fig. 18. Although some errors were observed between the actual and target values of residual stress, these errors were very small and could be ignored.

The curves of the buckling factor along with $\lambda_{\mathrm{n}}$ under the influence of residual stress are shown in Fig. 19. The yield strength of the adopted steel was set to 235, 345 and $610 \mathrm{MPa}$ to determine the influence of welding residual stress on angles with different yield strengths. The residual stress can reduce the buckling factor of short AWLs but can increase the buckling factor of AWLs with large slenderness ratios. The influence of residual stress on buckling factor increased along with the residual stress magnitude (i.e., the value of $\beta$ ). However, the change in the buckling factor between $0.3 f_{\mathrm{y}}$ and $0.7 f_{\mathrm{y}}$ was very small. Therefore, only $\beta=0.7$ was considered in the latter analysis. The results in Fig. 19 indicate that the influence of residual stress on AWLs with large slenderness ratios can be ignored for safety. Given that residual stress has a small influence on the buckling factor of AWLs with small slenderness ratios and that the value of $\beta$ in actual conditions is less than 0.7 , the influence of residual stress was ignored in this study for simplicity.

The failure modes $\left(\lambda_{\mathrm{n}}=0.07\right)$ corresponding to different values of $\sigma_{\mathrm{r}}$ are presented in Fig. 20. The residual stress magnitude directly influences the stress distribution at the failure state. The tensioning stress at the middle part of the AWL decreased along with an increasing $\sigma_{\mathrm{r}}$, thereby suggesting that the strength of the material at this location cannot be fully played out. In this case, the buckling capacity of the AWL is reduced.

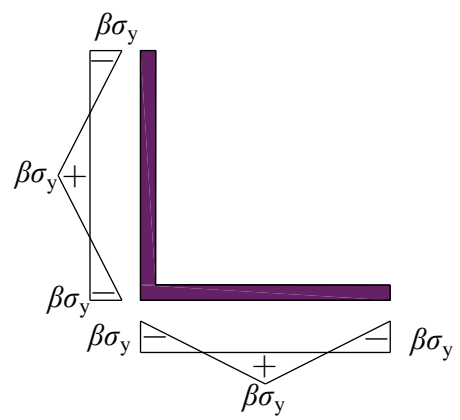

Fig. 17 Typical distribution mode of residual stres 


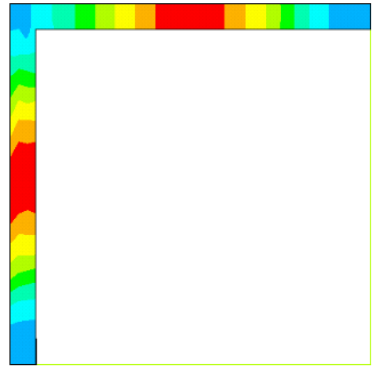

a) $\quad \sigma_{\mathrm{r}}=0.3 f_{\mathrm{y}}$
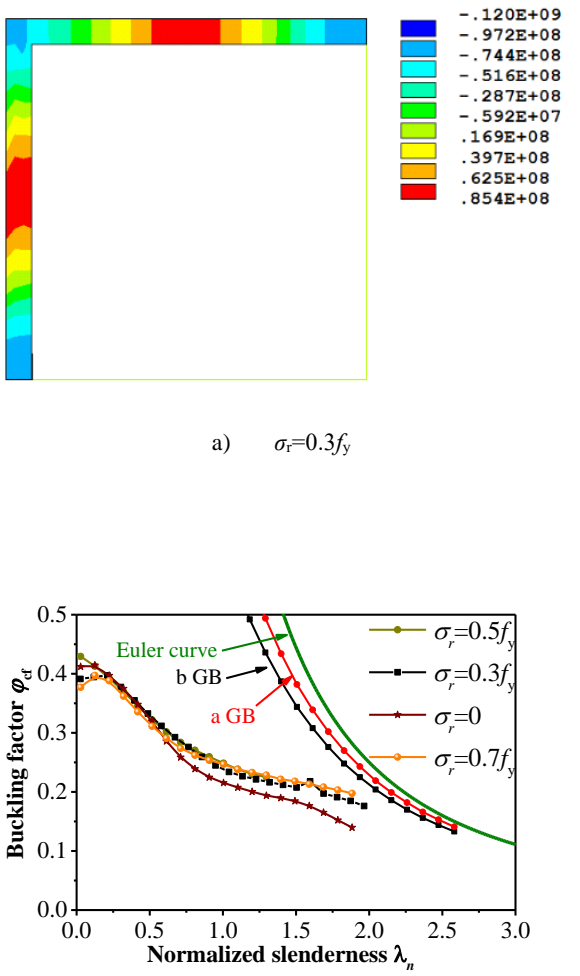

a) $f_{\mathrm{y}}=235 \mathrm{MPa}, L_{\mathrm{w}}=40 \mathrm{~mm}, L 70 \times 5$

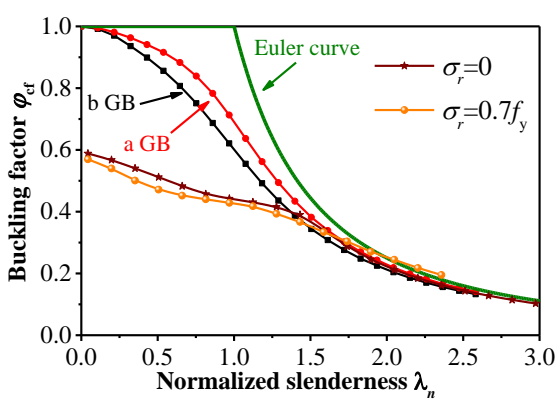

d) $f_{\mathrm{y}}=235 \mathrm{MPa}, L_{\mathrm{w}}=40 \mathrm{~mm}, L 45 \times 5$
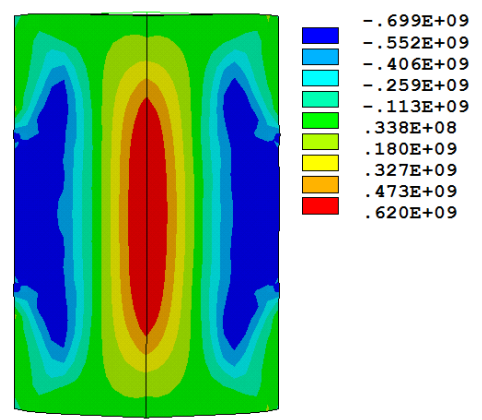

a) $\quad \sigma_{\mathrm{r}}=0$

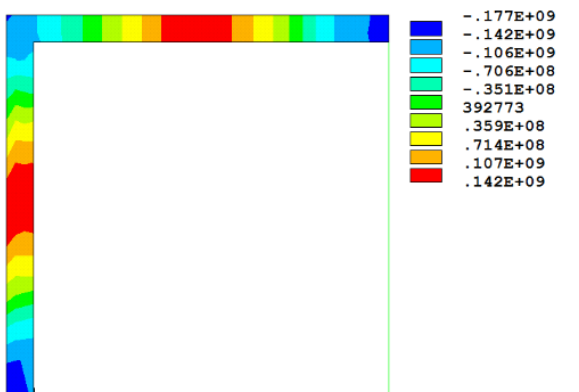

b) $\quad \sigma_{\mathrm{r}}=0.5 f_{\mathrm{y}}$

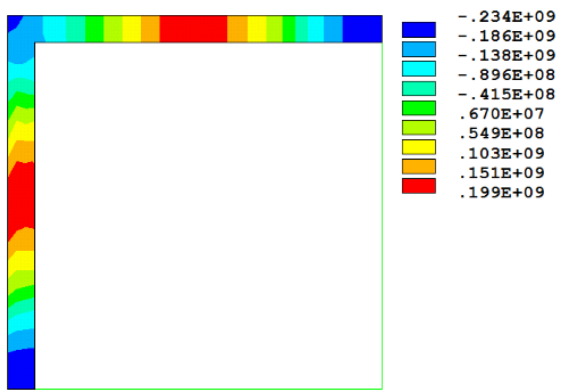

c) $\quad \sigma_{\mathrm{r}}=0.7 f_{\mathrm{y}}$

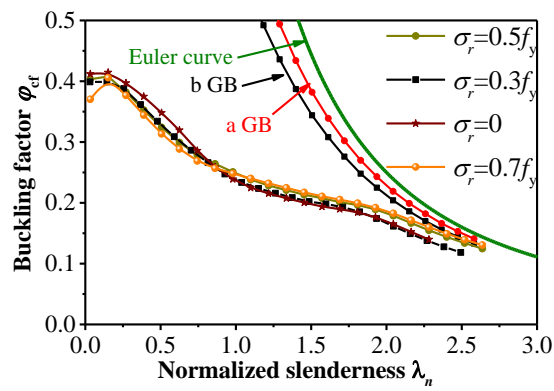

b) $f_{\mathrm{y}}=345 \mathrm{MPa}, L_{\mathrm{w}}=40 \mathrm{~mm}, L 70 \times 5$

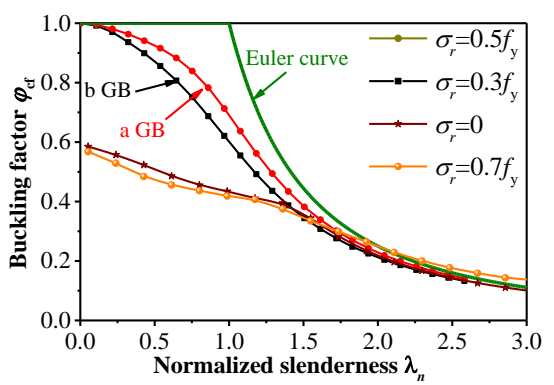

e) $f_{\mathrm{y}}=345 \mathrm{MPa}, L_{\mathrm{w}}=40 \mathrm{~mm}, L 45 \times 5$

Fig. 19 Influence of residual stress on buckling factor
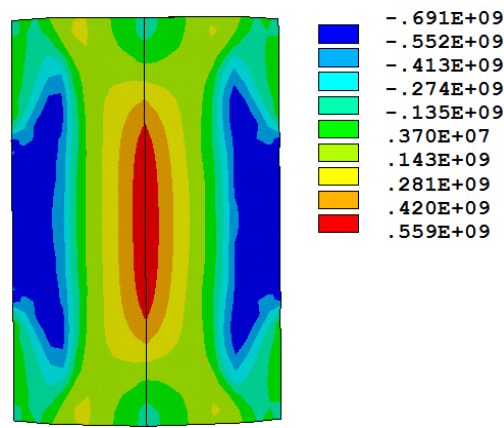

b) $\quad \sigma_{\mathrm{r}}=0.5 f_{\mathrm{y}}$

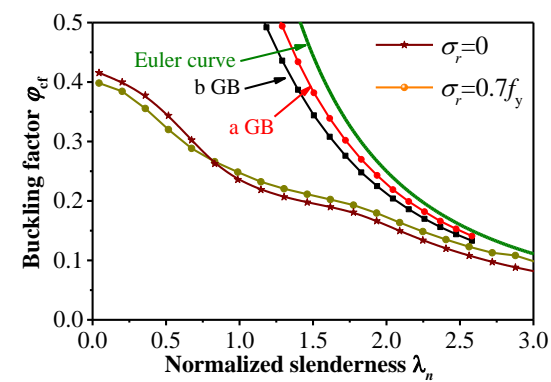

c) $f_{\mathrm{y}}=610 \mathrm{MPa}, L_{\mathrm{w}}=40 \mathrm{~mm}, L 70 \times 5$

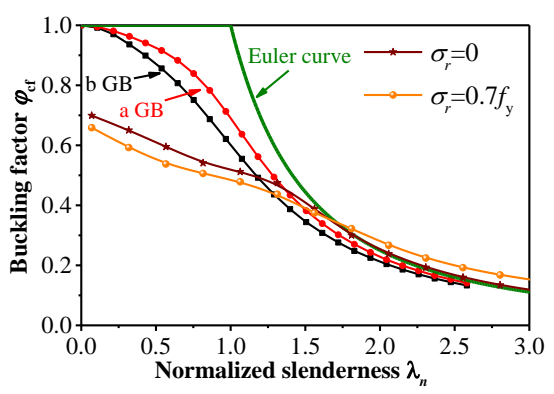

f) $f_{\mathrm{y}}=610 \mathrm{MPa}, L_{\mathrm{w}}=40 \mathrm{~mm}, L 45 \times 5$
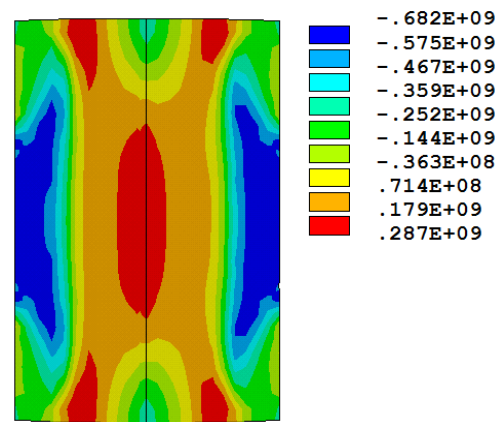

c) $\sigma_{\mathrm{r}}=0.7 f_{\mathrm{y}}$

Fig. 20 Failure modes corresponding to different values of $\sigma_{\mathrm{r}}\left(f_{\mathrm{y}}=610 \mathrm{MPa}\right)$

\section{Influence of weld length on buckling capacity}

\subsection{Effect of $L_{w}$ on buckling factor}

The weld length at both ends of an AWL can directly determine the constraint strength. The influence of weld length on the buckling capacity of AWLs was investigated in this section. The curves of buckling factor and $\lambda_{n}$ corresponding to different values of $L_{\mathrm{w}}$ are compared in Fig. 21 a, which was derived based on section $L 45 \times 5$. The maximum buckling factor was equal to $0.36,0.58,0.80$, and 1.0 when the values of $L_{\mathrm{w}}$ were $20,40,60$, and $80 \mathrm{~mm}$, respectively. The AWL was welded to the surface of the steel column, and the translational degree of weld is equal to 0 . Therefore, the constraint condition changed along with the values of $L_{\mathrm{w}}$, while the constraint induced by the weld was strengthened along with an increasing $L_{\mathrm{w}}$. The AWL was subjected to axial force when the value of $L_{\mathrm{w}}$ reached $200 \mathrm{~mm}$. The steel grade nearly had no influence on the buckling factor. Fig. $21 \mathrm{~d}$ shows that the buckling factor changes almost linearly along with $L_{\mathrm{w}}$ for $L 70 \times 5$, while the AWL with section $L 70 \times 5$ is subjected to axial force when the value of $L_{\mathrm{w}}$ is twice larger than that of $w$. In other words, the AWL can be seen as an axial compression bar when the length of the weld is twice larger than the value of $w$. 


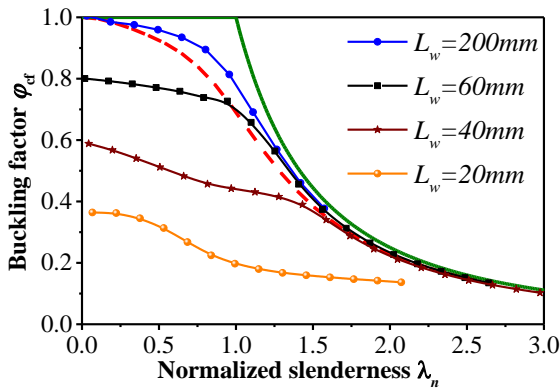

a) $f_{\mathrm{y}}=235 \mathrm{MPa}, L 45 \times 5$

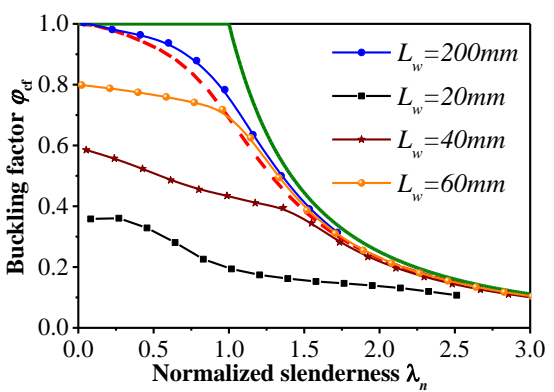

b) $f_{\mathrm{y}}=345 \mathrm{MPa}, L 45 \times 5$

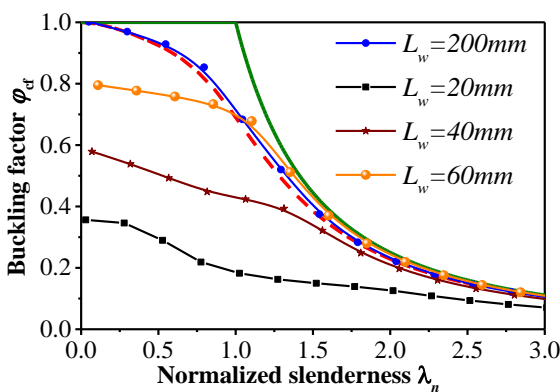

c) $f_{\mathrm{y}}=610 \mathrm{MPa}, L 45 \times 5$

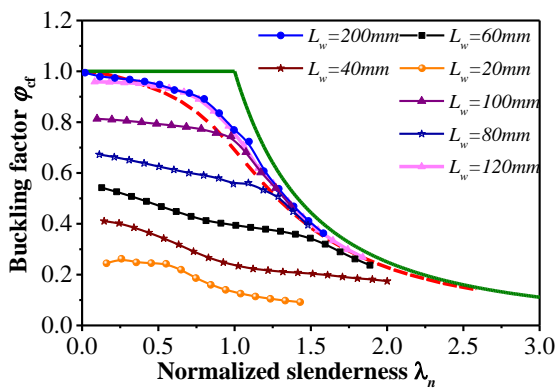

d) $f_{\mathrm{y}}=235 \mathrm{MPa}, L 70 \times 5$

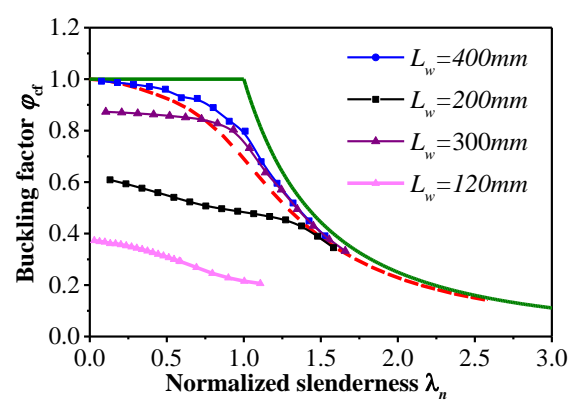

e) $f_{\mathrm{y}}=235 \mathrm{MPa}, L 200 \times 20$

Fig. 21 Influence of $L_{\mathrm{w}}$ on buckling factor

\subsection{Effect of constraint condition on buckling factor}

Only the translational degree of the weld was constrained in the above analysis. The translational degrees of the unwelded zone at the top and bottom of the AWL were not constrained because this zone was not directly connected to the steel column as shown in Fig. 6. However, the translational degree of the unwelded zone could be constrained by the steel column in a certain degree. Therefore, the translation degree of the unwelded zone was constrained to

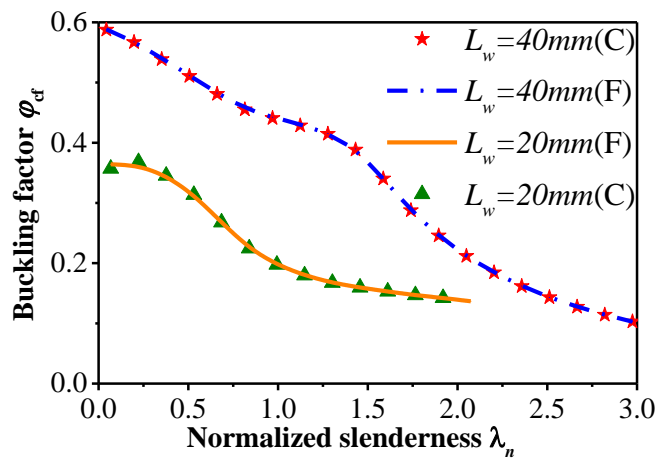

a) $f_{\mathrm{y}}=235 \mathrm{MPa}, L 45 \times 5$ investigate its influence on the buckling factor of AWLs. The symbols " $\mathrm{C}$ " and "F" denote that the translational degrees of the unwelded zone are restrained and not restrained, respectively. The results are presented in Fig. 22, where the symbols " $C$ " and " $F$ " denote that the translation degree of the unwelded zone is fixed and not constrained, respectively. Given that the translational degree does not have any influence on the buckling factor of AWLs, this influence can be neglected.

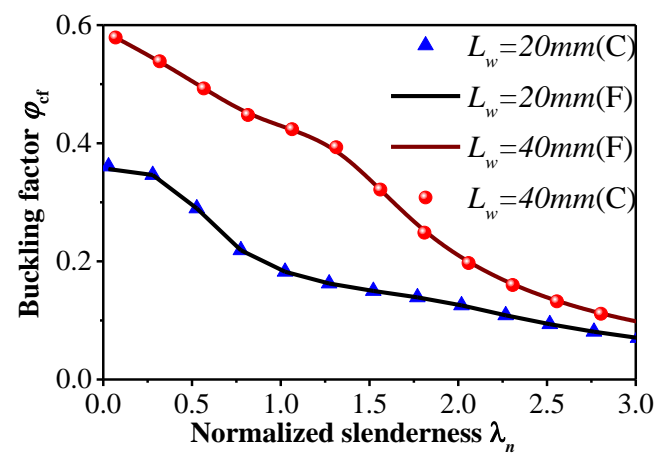

b) $\quad f_{\mathrm{y}}=610 \mathrm{MPa}, L 45 \times 5$

Fig. 22 Influence of constraint condition on buckling factor

\subsection{Effect of $L_{w}$ on failure mode}

The effect of $L_{\mathrm{w}}$ on the failure mode of angle was systematically investigated in this section. The overall length of AWL $(L)$ was set to $0.6 \mathrm{~m}$, while the length of the weld zone $\left(L_{\mathrm{w}}\right)$ was set to different values. The thicknesses of AWL $(T)$ were set to $3 \mathrm{~mm}$ and $8 \mathrm{~mm}$. The restraint conditions of the top and bottom of the angle were set to pined-pinned (the translational degree of the unwelded zone was not restrained) and fixed-fixed (the translational degree of the unwelded zone was fixed), respectively, to investigate the influence of the constraint condition on the mechanical behavior of the angle. The load-displacement curves of AWLs with different $L_{\mathrm{w}}$ are presented in Fig. 23 and Fig. 24. The loading capacity of AWL increased along with the value of $L_{\mathrm{w}}$. Material strength can be fully played out when the $L_{\mathrm{w}}$ exceeds $100 \mathrm{~mm}$. The AWL seemed to be an axially compressed bar when $L_{\mathrm{w}}$ was sufficiently large. A rigid loading region could also be formed at two sides of the AWL when the $L_{\mathrm{w}}$ was sufficiently large to ensure that the ultimate loading capacity could be reached. The loading capacity of the AWL also linearly decreased along with thickness $(T)$ in the two constraint conditions.

The von Mises stress of AWL is presented in Fig. 25 and Fig. 26. The stress level at the middle part of the AWL was very low when $L_{\mathrm{w}}$ was equal to $10 \mathrm{~mm}$ Meanwhile, the stress level at the low stress zone increased along with $L_{\mathrm{w}}$. The size of the low stress zone also decreased along with increasing $L_{\mathrm{w}}$. A rigid loading region could be formed at two sides of the AWL when $L_{\mathrm{w}}$ was sufficiently large. The stress was uniformly distributed at the middle part of the AWL.

The results derived in these two constraint conditions are compared in Fig. 27. The constraint condition almost had no influence on loading capacity when $L_{\mathrm{w}}$ exceeded $100 \mathrm{~mm}$. The constraint condition could be seen as fixed-fixed when $L_{\mathrm{w}}$ exceeded $100 \mathrm{~mm}$. The constraint condition also had a slight influence on loading capacity when $L_{\mathrm{w}}$ was equal to $10 \mathrm{~mm}$ and $15 \mathrm{~mm}$. Therefore, the constraint conditions had minimal influence on axial loading capacity when $L_{\mathrm{w}}$ was not sufficiently large.

The development of stress in the length direction during the loading process is illustrated in Fig. 28. The value of $L_{w}$ was set to $200 \mathrm{~mm}$ in this analysis. The strength of the material between welded zones can be fully played out. Given that the buckling of limb can occur after the full section is yielded, the material strength can be fully played out by using intermittent weld. 


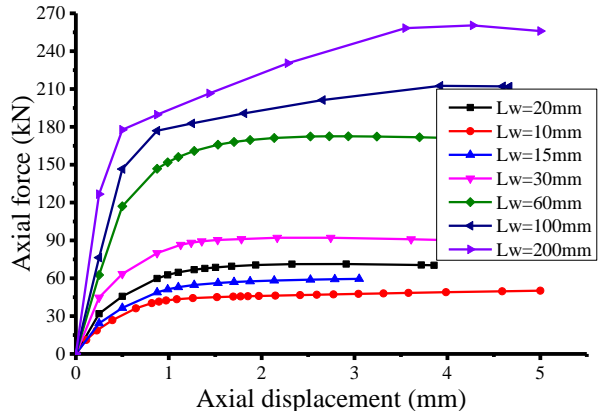

a) $\quad T=8 \mathrm{~mm}, L=0.6 \mathrm{~m}$

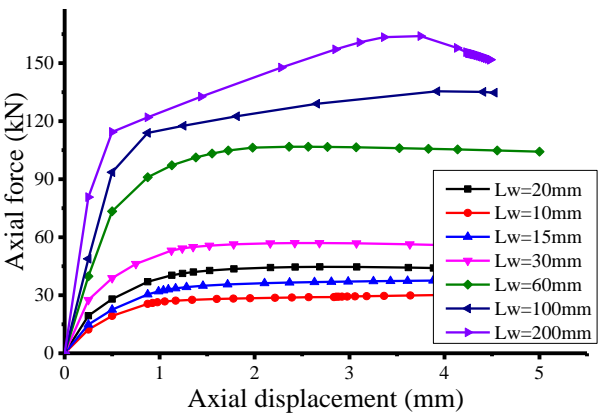

b) $\quad T=5 \mathrm{~mm}, L=0.6 \mathrm{~m}$

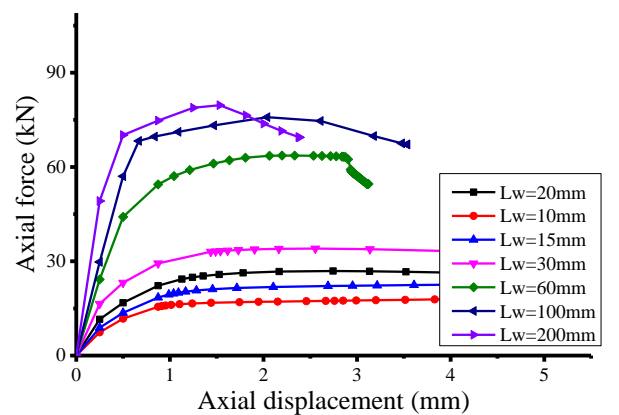

c) $\quad T=3 \mathrm{~mm}, L=0.6 \mathrm{~m}$

Fig. 23 Influence of weld length on loading capacity (pined-pinned condition)

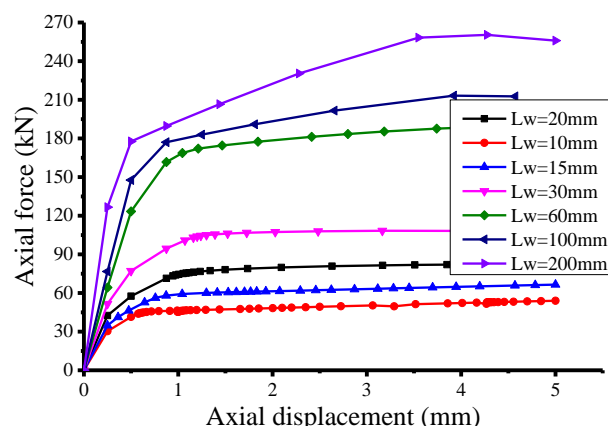

a) $\quad T=8 \mathrm{~mm}, L=0.6 \mathrm{~m}$

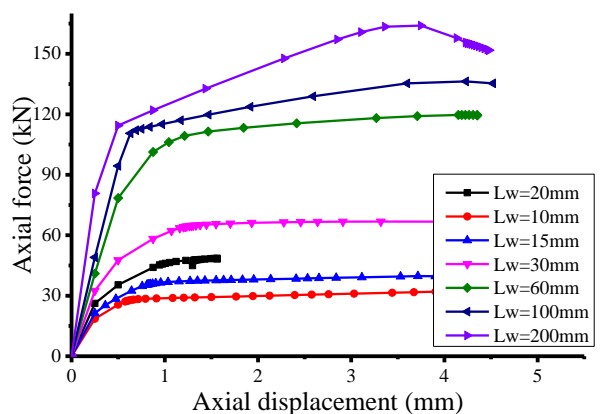

b) $\quad T=5 \mathrm{~mm}, L=0.6 \mathrm{~m}$

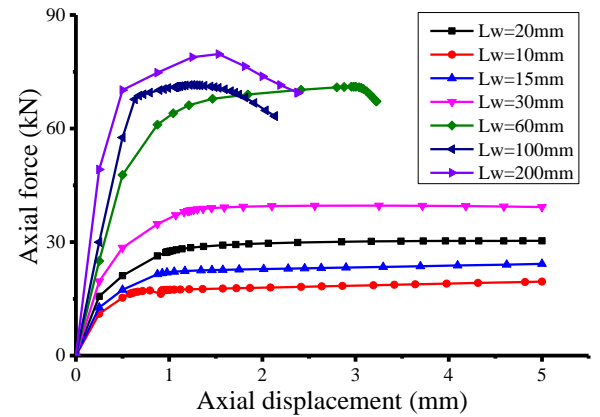

c) $\quad T=3 \mathrm{~mm}, L=0.6 \mathrm{~m}$

Fig. 24 Influence of weld length on loading capacity (fix-fixed condition)

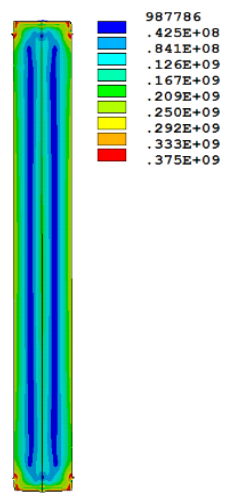

a) $\quad L_{\mathrm{w}}=10 \mathrm{~mm}$

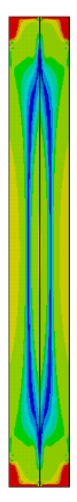

b)

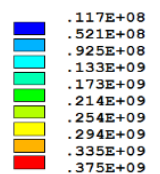

$L_{\mathrm{w}}=30 \mathrm{~mm}$

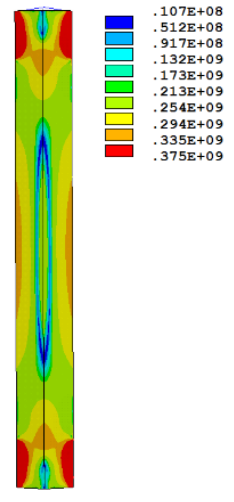

c) $\quad L_{\mathrm{w}}=60 \mathrm{~mm}$

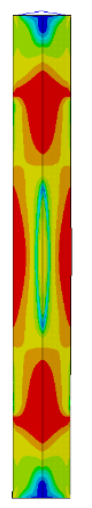

d) $L_{\mathrm{w}}=100 \mathrm{~mm}$ formed
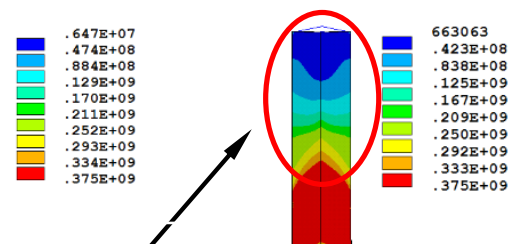

Rigid loading region

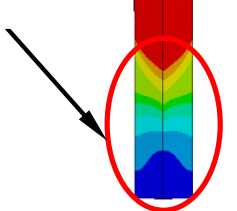

e) $L_{\mathrm{w}}=200 \mathrm{~mm}$

Fig. 25 Failure modes of angles with different weld lengths $(T=8 \mathrm{~mm}, L=0.6 \mathrm{~m})$

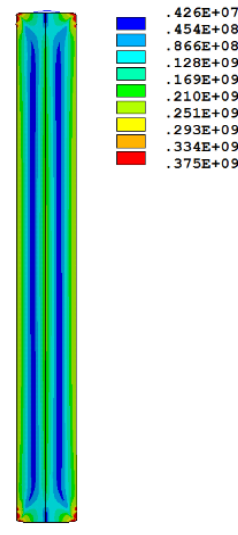

a) $\quad L_{\mathrm{w}}=10 \mathrm{~mm}$

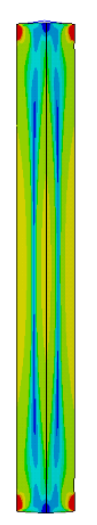

b) $\quad L_{\mathrm{w}}=20 \mathrm{~mm}$
$.333 E+09$

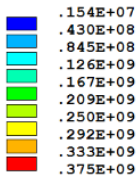

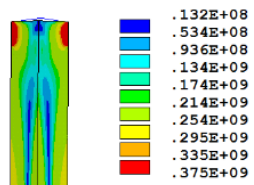

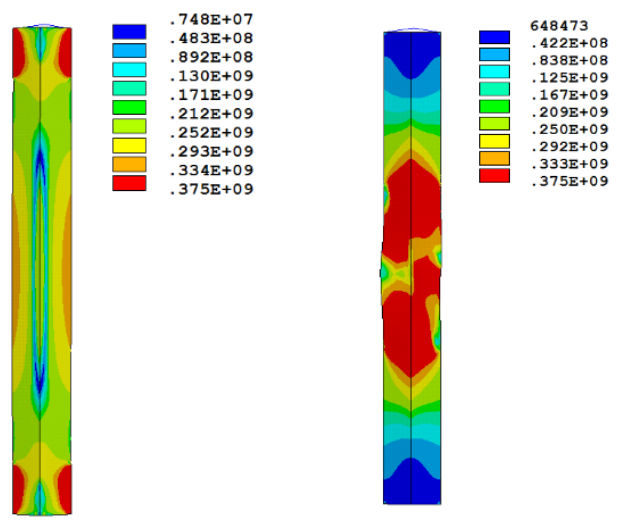

d) $L_{\mathrm{w}}=60 \mathrm{~mm}$

e) $L_{\mathrm{w}}=200 \mathrm{~mm}$

Fig. 26 Failure modes of angles with different weld lengths ( $T=3 \mathrm{~mm}, L=0.6 \mathrm{~m})$ 


\section{Influence of sectional dimension and steel grade}

\subsection{Effects of sectional dimension on buckling capacity}

The aforementioned results indicated that the sectional dimension could significantly influence the buckling factor of AWL. The yield strength $f_{\mathrm{y}}$ was set to $235 \mathrm{MPa}$. The section typically adopted in actual projects was systematically investigated. Fig. 29 shows that the buckling factor significantly decreases along with an increasing $w$. This finding can be attributed to the fact that the additional

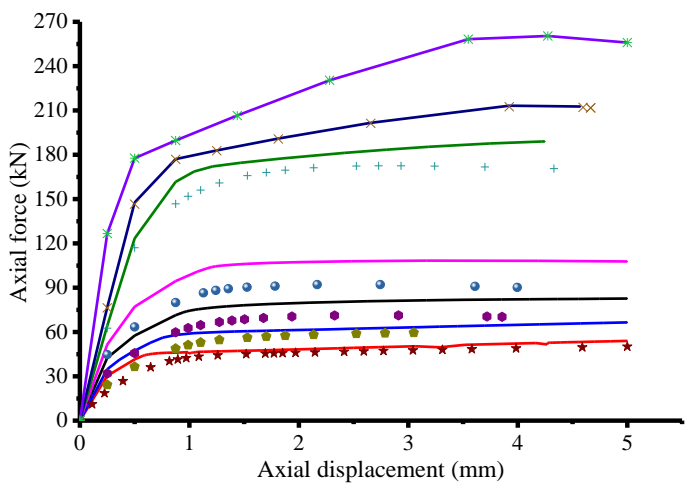

a) $\quad T=8 \mathrm{~mm}, L=0.6 \mathrm{~m}$ moment caused by the bias of load increases along with $w$. The curves of buckling factor and $\lambda_{\mathrm{n}}$ approached the Euler curve as $\lambda_{\mathrm{n}}$ continued to increase, thereby indicating that the failure mode was transformed from strength failure to buckling failure after $\lambda_{\mathrm{n}}$ reached a certain value. The bias of load could be neglected at that time and the AWL seemed to be subjected to axial force. AWL with different thicknesses are compared in Fig. 29 c. Given that the shear stiffness of the welded zone increased along with $t$, the buckling factor of AWL increased along with $t$ when the value of $w$ was kept constant.

Fig. 27 Comparison of the results derived in different constraint conditions
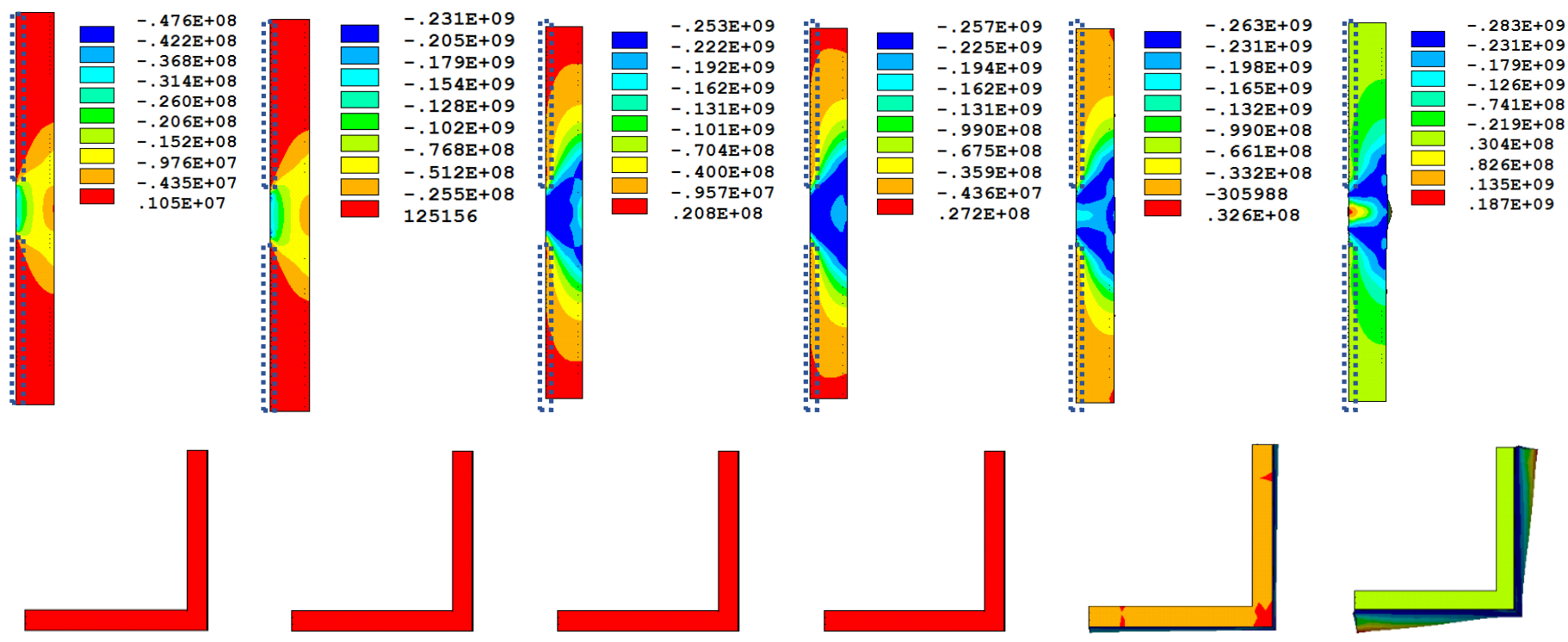

Fig. 28 Development of vertical stress during the loading process (Unit: Pa)

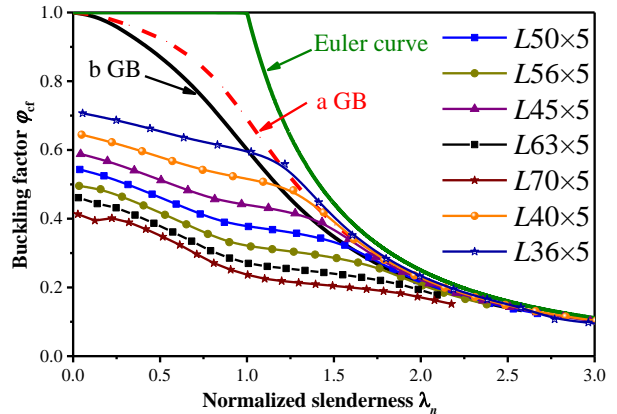

a) $f_{\mathrm{y}}=235 \mathrm{MPa}, L_{\mathrm{w}}=40 \mathrm{~mm}, t=5 \mathrm{~mm}$

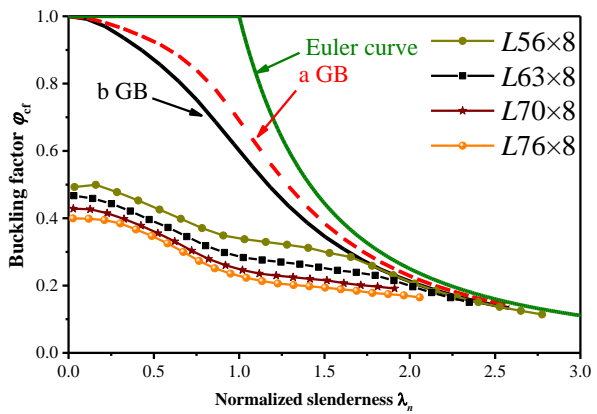

b) $f_{\mathrm{y}}=235 \mathrm{MPa}, L_{\mathrm{w}}=40 \mathrm{~mm}, t=8 \mathrm{~mm}$

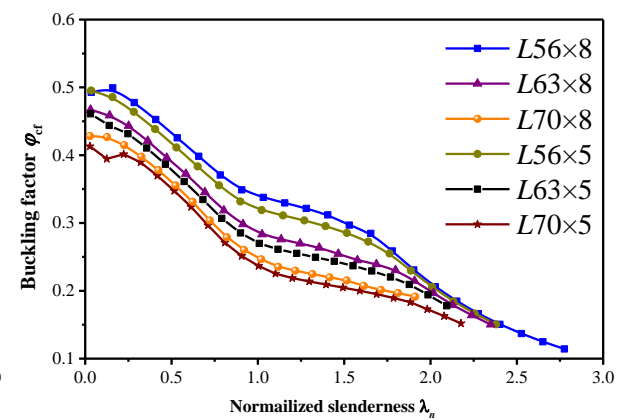

c) Comparison of AWL with different sections

Fig. 29 The influence of $w / t$ ratios on buckling capacity

\subsection{Effects of steel grades $\left(f_{y}\right)$ on buckling capacity}

High-strength steel has been widely utilized along with the advancements in material science. The possible influence of yield strength $f_{\mathrm{y}}$ on buckling factor was investigated in this section. The sectional dimensions were set to $L 70 \times 5$ and
$L 75 \times 8$, while the values of $f_{\mathrm{y}}$ were set to $235,345,410$, and $610 \mathrm{MPa}$. The curves of the buckling factor along with $\lambda_{\mathrm{n}}$ are shown in Fig. 30.

The yield strength $f_{\mathrm{y}}$ has a very slight influence on the buckling factor of AWL, especially for $L 70 \times 5$ and $L 75 \times 8$. Therefore, the influence of $f_{\mathrm{y}}$ on the buckling factor of AWL can be neglected. 


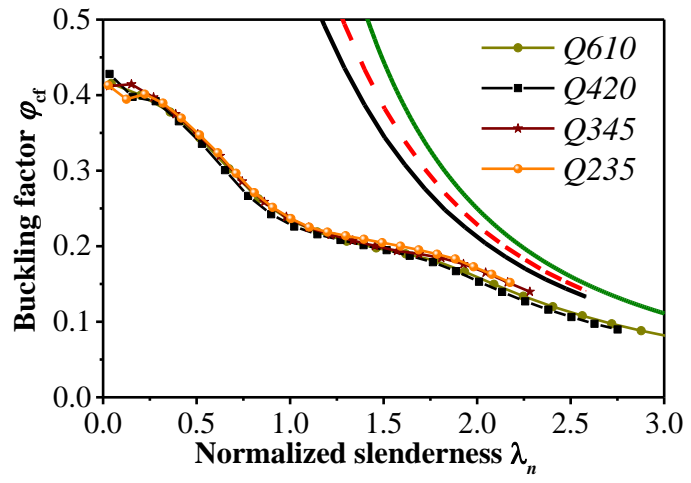

a) $\quad t=5 \mathrm{~mm}, L_{\mathrm{w}}=40 \mathrm{~mm}, L 70 \times 5$

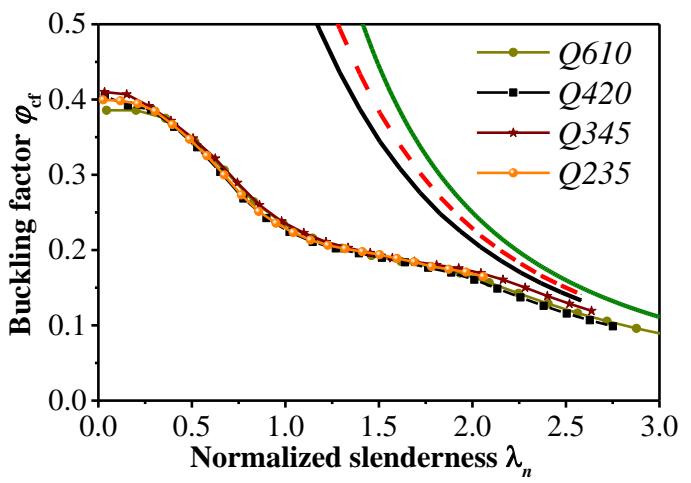

b) $\quad t=8 \mathrm{~mm}, L_{\mathrm{w}}=40 \mathrm{~mm}, L 75 \times 8$

Fig. 30 Influence of $f_{\mathrm{y}}$ on buckling factor

\section{Conclusions}

The angles welded by intermittent weld have been widely utilized in pratical engineering, such as the strengthening of steel column presented in this work. However, the mechanical behavior of angles welded by intermittent weld has not been clearly clarified. There is no guidance for the design of angles welded by intermittent weld, such as the weld length $\left(L_{\mathrm{w}}\right)$ and the intermintent distance. The work presented is performed based on this background. The mechanical behavior of AWLs that are used for strengthening steel box columns was investigated in this paper and their buckling factor was systematically computed. The influence of $L_{\mathrm{w}}, f_{\mathrm{y}}$, residual stress, and initial geometrical imperfection was also studied. The conclusions are summarized as follows:

1) The influence of initial geometrical imperfection on the buckling factor of AWLs can be neglected, and residual stress has a slight influence on buckling factor. However, residual stress has different effects on AWLs with small and large slenderness.

2) The AWL seems to be an axial compression bar when the value of $L_{w}$ is twice larger than the width of AWL. The buckling factor can be obtained through curve a in GB 50017-2003 for safety.

3) The constraint condition at both ends of the AWL has a minimal influence on axial loading capacity when the value of $L_{\mathrm{w}}$ is not sufficiently large. This finding can be ascribed to the fact that the constraint from the weld is not strong enough when $L_{\mathrm{w}}$ has a small value.

4) The comparison among AWLs with different thicknesses reveals that the buckling factor of AWL increases along with $t$ while the value of $w$ is kept constant.

5) The curves of the buckling factor and $\lambda_{\mathrm{n}}$ approach the Euler curve as $\lambda_{n}$ continues to increase. This finding indicates that the failure mode changes from strength failure to buckling failure after $\lambda_{n}$ reaches a certain value. The bias of load can be neglected and the AWL seems to be subjected to axial force.

\section{Acknowledgements}

The work described in this paper was financially supported by the State Key Research Development Program of China (Grant Nos. 2016YFC0801404 and 2016YFC0600704) and Basic Research Project of Education Department of Liaoning Province (LJ2020JCL036).

\section{References}

[1] H.Fukuyama; S.Sugano. Japanese seismic rehabilitation of concrete buildings after the hyogoken-nanbu earthquake. Cement and Concrete Composites, 2000, 22(1): 59-79.

[2] Garzón-Roca, Julio;Ruiz-Pinilla, Joaquín;Adam, Jose M.; Calderón, Pedro A. An experimental study on steel-caged RC columns subjected to axial force and bending moment. Engineering Structures, 2011, 33(2): 580-590.

[3] Yang Yuan, Chen Zhihua, Zhao Zhongwei, Liu Xiaoke. Axial compression performance of steel box columns with different strengthening schemes. International journal of steel structures, 2017, 17(2): 367-378

[4] Zhongwei Zhao, Haiqing Liu, Bing Liang. Mechanical behavior of angle used in strengthening of rectangular column $[\mathrm{J}]$. Structures and Buildings, 2019. (DOI $10.1680 /$ jstbu. 18.00076$)$

[5] G. Campione; A. Monaco(1); M. Papia. Simplified analytical model for moment-axial force domain in the presence of shear in R.C. members externally strengthened with steel cages. Materials and Structures, 2016, 49(8): 3143-3157.

[6] Campione G. Analytical model for high strength concrete columns with square cross-section. Structural engineering and mechanics, 2008, 28(3): 295-316.

[7] Adam JM; Ivorra S; Gimenez E; Moragues JJ; Miguel P; MirAgall C; Calderon PA. Behaviour of axially loaded RC columns strengthened by steel angles and strips. Steel and composite structures, 2007, 7(5): 405-19.

[8] Adam JM; Giménez E; Calderón PA; Pallarés FJ; Ivorra S. Experimental study of beamcolumn joints in axially loaded RC columns strengthened by steel angles and strips. Steel and composite structures, 2008, 8(4): 329-42.

[9] R.C. Spoorenberg, H.H. Snijder, L.G. Cajot, N. Popa, Buckling curves for heavy wide flange QST columns based on statistical evaluation, J. Constr. Steel Res. 101 (2014) 280-289.

[10] J. Jönsson, T.C. Stan, European column buckling curves and finite elementmodelling including high strength steels, J. Constr. Steel Res. 128 (2017) 136-151.

[11] D. Chen, J. Yang, S. Kitipornchaia. Buckling and bending analyses of a novel functionally graded porous plate using Chebyshev-Ritz method. Archives of Civil and Mechanical Engineering, 19(1): 157-170

[12] M. Bodaghi, A.R. Damanpack, G.F. Hu, W.H. Liao. Large deformations of soft metamaterials fabricated by 3D printing. Materials \& Design, 2017, 131: 81-91.

[13] Marian Antoni Giżejowski, Radosław Szczerba, Marcin Daniel Gajewski, Zbigniew Stachura. Buckling resistance assessment of steel I-section beam-columns not susceptible to LTbuckling. Archives of Civil and Mechanical Engineering, 2017, 17(2): 205-221.

[14] A. Hussain, Zuo-Lei Du, Yao-Peng Liu and Siu-Lai Chan, Stability design of single angle member using effective stress-strain method. Structures, 2019 (20): p. 298-308

[15] A. Hussain, Yao-Peng Liu and Siu-Lai Chan, Stability design of single angle member using effective stress-strain method. Advances in Structural Engineering, 2020, Vol. 23(10) 2121 2135 .

[16] H. Ban, G. Shi, Overall buckling behaviour and design of high-strength steel welded section columns, J. Constr. Steel Res. 143 (2018) 180-195. doi:10.1016/j.jcsr.2017.12.026.

[17] T.J. Li, G.Q. Li, S.L. Chan, Y.B. Wang, Behavior of Q690 high-strength steel columns: part 1: experimental investigation, J. Constr. Steel Res. 123 (2016) 18-30.

[18] T.J. Li, S.W. Liu, G.Q. Li, S.L. Chan, Y.B. Wang, Behavior of Q690 high-strength stee columns: part 2: parametric study and design recommendations, J. Constr. Steel Res. 122 (2016) 379-394

[19] S.D. Nie, S.B. Kang, L. Shen, B. Yang, Experimental and numerical study on global buckling of Q460GJ steel box columns under eccentric compression, Eng. Struct. 142 (2017) 211-222.

[20] Katalin Oszvald, Pál Tomka, László Dunai. The remaining load-bearing capacity of corroded steel angle compression members. Journal of Constructional Steel Research, 2016, 120: 188198.

[21] Kulatung M.P., Macdonald M., Rhodes J., Harrison D.K.. Load capacity of cold-formed column members of lipped channel cross-section with perforations subjected to compression loading - Part I: FE simulation and test results. Thin-Walled Structures, 2014, 80: 1-12.

[22] Lip H. Teh, and Benoit P. Gilbert. Net Section Tension Capacity of Cold-Reduced Sheet Stee Angle Braces Bolted at One Leg. Journal of Structural Engineering, 2013, 139(3): 328-337.

[23] Maia W.F., Vieira Jr. L.C.M., Schafer B.W., Malite M.. Experimental and numerica investigation of cold-formed steel double angle members under compression. Journal of Constructional Steel Research, 2016, 121: 398-412.

[24] GB 50017-2017, Code for Design of Steel Structures, China Architecture \& Building Press, Beijing, 2006.

[25] N.S. Trahair, M.A. Bradford, D.A. Nethercot, L. Gardner, The Behaviour and Design of Stee Structures to EC3, 4th edn Spon Press, London, 2008 